\title{
The Effect of Zn-Al-Hydrotalcites Composited with Calcium Stearate and $\beta$-Diketone on the Thermal Stability of PVC
}

\author{
Mengliang Tong ${ }^{1}$, Hongyan Chen ${ }^{2}$, Zhanhong Yang ${ }^{2, *}$ and Runjuan Wen ${ }^{2}$ \\ 1 Hunan Chemical Vocational and Technical College, Zhuzhou 412004, China; \\ E-Mail: 13973327103@163.com \\ 2 College of Chemistry and Chemical Engineering, Central South University, Changsha 410083, \\ China; E-Mails: chykn0@163.com (H.C.); wrj20050440076@163.com (R.W.) \\ * Author to whom correspondence should be addressed; E-Mail: zhyang@ mail.csu.edu.cn; \\ Tel.: +86-731-88879616.
}

Received: 26 January 2011; in revised form: 9 February 2011 / Accepted: 7 March 2011 / Published: 8 March 2011

\begin{abstract}
A clean-route synthesis of Zn-Al-hydrotalcites (Zn-Al-LDHs) using zinc oxide and sodium aluminate solution has been developed. The as-obtained materials were characterized by X-ray diffraction (XRD), Fourier transform infrared spectroscopy (FT-IR), and scanning electron microscopy (SEM). The effects of metal ions at different molar ratios on the performance of hydrotalcites were discussed. The results showed that the $\mathrm{Zn}$-Al-hydrotalcites can be successfully synthesized at three different $\mathrm{Zn} / \mathrm{Al}$ ratios of 3:1, 2:1 and 1:1. Thermal aging tests of polyvinyl chloride (PVC) mixed with Zn-Al-LDHs, calcium stearate $\left(\mathrm{CaSt}_{2}\right)$ and $\beta$-diketone were carried out in a thermal aging test box by observing the color change. The results showed that $\mathrm{Zn}-\mathrm{Al}-\mathrm{LDH}$ can not only enhance the stability of PVC significantly due to the improved capacity of $\mathrm{HCl}$-adsorption but also increase the initial stability and ensure good-initial coloring due to the presence of the $\mathrm{Zn}$ element. The effects of various amounts of $\mathrm{Zn}$-Al-LDHs, $\mathrm{CaSt}_{2}$ and $\beta$-diketone on the thermal stability of PVC were discussed. The optimum composition was determined to be $0.1 \mathrm{~g} \mathrm{Zn-Al-LDHs,}$ $0.15 \mathrm{~g} \mathrm{CaSt}_{2}$ and $0.25 \mathrm{~g} \beta$-diketone in $5 \mathrm{~g} \mathrm{PVC}$.
\end{abstract}

Keywords: Zn-Al-LDHs; polyvinyl chloride; stabilizer 


\section{Introduction}

Chlorine-containing polymers such as polyvinyl chloride (PVC) are widely used in many fields, namely, in water pipes, floor and roof tiles, packing films and sheets, due to their advantages of a non-flammable nature, good performance and low price [1]. However, under the influence of elevated temperature and UV radiation, PVC undergoes an autocatalytic dehydrochlorination reaction, which results in severe discoloration and loss of some properties [2]. Stabilizers can inhibit the degradation of removal of $\mathrm{HCl}$ due to their capacity for $\mathrm{HCl}$-adsorption. Although the main used thermal stabilizers are lead salts, metal soaps, organo-tin compounds and rare earth compounds [3-4], these stabilizers have some drawbacks of toxicity, environmental pollution and high cost. Hence, it is necessary to explore an environmentally friendly stabilizer with non-toxicity, economical interest and high efficiency.

Layered double hydroxides (LDHs) are a class of synthetic two-dimensional nanostructured anionic clays with a hydrotalcite (HT)-like structure [5]. LDHs are represented by the general formula $\left[\mathrm{M}^{2+}{ }_{1-x} \mathrm{M}{ }^{3+}{ }_{x}(\mathrm{OH})_{2}\right]^{x+}\left(\mathrm{A}^{n-}\right)_{x / n} m_{2} \mathrm{O}$, where $\mathrm{M}^{2+}(\mathrm{M}=$ e.g., $\mathrm{Mg}, \mathrm{Fe}, \mathrm{Co}, \mathrm{Cu}, \mathrm{Ni}$, or $\mathrm{Zn})$ and $\mathrm{M}^{3+}$ ( $\mathrm{M}=$ e.g., $\mathrm{Al}, \mathrm{Cr}, \mathrm{Ga}, \mathrm{Mn}$ or $\mathrm{Fe}$ ) are di-and trivalent cations, respectively; the value of $x$ is equal to the molar ratio of $\mathrm{M}^{2+} /\left(\mathrm{M}^{2+}+\mathrm{M}^{3+}\right)$, which is generally in the range of $0.2-0.33 ; \mathrm{A}^{n-}$ is an anion. Substitution of divalent cations by trivalent cations can result in a positive charge on the layers. So organic or inorganic anions are intercalated between the layers in order to maintain charge balance, and the water of crystallization is also generally found in the interlayer galleries [6-7]. There are many techniques for the preparation of LDHs. The most commonly used method is simple co-precipitation, some other methods, such as rehydration, hydrothermal reaction, pre-pillaring and intercalation, were also reported [8]. Due to their acidic and alkaline characteristics, memory effect, large surface area, high anion exchange and good thermal stability, LDHs present a good prospect for the application in catalysis, ion-exchange, adsorption, pharmaceutics, photochemistry and electrochemistry [9]. Moreover, the largest application of LDHs materials is in the polymer industry, mainly related to stabilizing PVC [10-12].

$\mathrm{Mg}-\mathrm{Al}-\mathrm{CO}_{3}-\mathrm{LDHs}$ have been reported to incorporate into PVC matrices with other organic salt stabilizers, such as $\mathrm{Ca}, \mathrm{Zn}$ and $\mathrm{Sn}$ stearates, which can improve the thermal stability of PVC significantly [13-14].However, because of the introduction of $\mathrm{Mg}$, the PVC samples with Mg-Al-LDHs have much weaker transparency resulting in yellowish appearance, which cannot meet the demands of plastic in the food industry, where colorless and odorless products are needed. Though this problem can be alleviated with the addition of zinc stearate to a certain degree, it was not resolved fundamentally. In order to achieve a product with initial thermal stability and transparency, the addition of $\mathrm{Mg}$ element was forbidden and $\mathrm{Mg}$ element should be replaced by $\mathrm{Zn}$ element [15].

Co-precipitation is the most common method used in the fabrication of LDHs. However, the products prepared showed low crystalline and fine particles, which needed further complex and various treatments of aging, hydrothermal reaction and so on. In addition, $\mathrm{NaOH}$ was consumed vastly, which can react with $\mathrm{Cl}^{-}, \mathrm{NO}_{3}{ }^{-}$and $\mathrm{SO}_{4}{ }^{-}$in the raw material forming $\mathrm{NaCl}, \mathrm{NaNO}_{3}$ and $\mathrm{Na}_{2} \mathrm{SO}_{4}$, which then can be released into the environment in large quantity.

In this work, the hydrotalcites were synthesized by a clean-route using zinc oxide and sodium aluminate solution. When replacing $\mathrm{ZnCl}_{2}, \mathrm{Zn}\left(\mathrm{NO}_{3}\right)_{2}, \mathrm{ZnSO}_{4}$ with $\mathrm{ZnO}$, zero release of $\mathrm{NaCl}, \mathrm{NaNO}_{3}$ 
and $\mathrm{Na}_{2} \mathrm{SO}_{4}$ was achieved. The effects of various molar ratios of $\mathrm{Zn} / \mathrm{Al}$ on the synthesis of $\mathrm{Zn}$-Al-LDHs were studied. Moreover, the synergistic effect of LDHs, metal soap $\left(\mathrm{CaSt}_{2}\right)$ and $\beta$-diketones were discussed in detail.

\section{Results and Discussion}

\subsection{Characterization of the $\mathrm{Zn}-\mathrm{Al}-\mathrm{LDHs}$}

\subsubsection{X-ray Diffraction (XRD) Analysis of Zn-Al-LDHs}

The XRD patterns of Zn-Al-LDHs with different $\mathrm{Zn}$-Al molar ratios are exhibited in Figure 1. The strong peaks at $11.2^{\circ}, 23.5^{\circ}, 35.1^{\circ}, 61.8^{\circ}$ are characteristic of a layered structure. The sharp and symmetrical diffraction peaks with a low and stable baseline indicate the well-crystallized layered structure of the Zn-Al-LDHs. It can be found that the XRD patterns of Zn-Al-LDHs with different $\mathrm{Zn} / \mathrm{Al}$ molar ratios are similar. The LDHs can be successfully synthesized with three different $\mathrm{Zn} / \mathrm{Al}$ ratios of 3:1, 2:1 and 1:1. According to $a=2 \mathrm{~d}_{110}$, the crystal structure of Zn-Al-LDHs with different molar ratios are the same. The charge number of $\mathrm{Al}^{3+}$ is greater than that of $\mathrm{Zn}^{2+}$, hence, the distance of the layers increases and the coulomb repulsion between metal ions in the adjacent hexagonal unit cells decreases with increasing the $\mathrm{Zn} / \mathrm{Al}$ ratio, making the lattice parameter $a$ and $c\left(=3 \mathrm{~d}_{003}\right)$ increase, especially $c$. This is based on the fact that parameter $a$ is a function of the average radius of the metal cations while parameter $c$ is a function of the average charge of the metal cations [14]. From Figure 1 the diffraction peak of curve $b$ is more sharp than that of a and c, indicating that the Zn-Al-LDHs has high crystallinity and integrated crystalline structures with molar ratio of $2: 1$.

Figure 1. (a) The XRD patterns of $\mathrm{Zn}-\mathrm{Al}-\mathrm{LDHs}$ with $\mathrm{Zn} / \mathrm{Al}$ molar ratios of 1:1; (b) 2:1; and (c) $3: 1$.

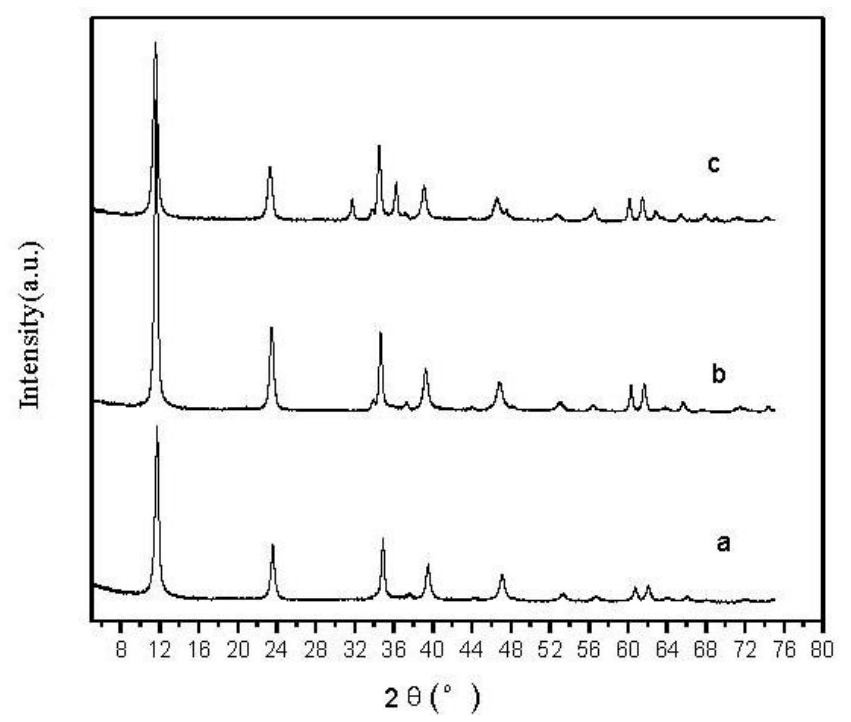

\subsubsection{Fourier Transform Infrared Spectroscopy (FT-IR) Analysis of Zn-Al-LDHs}

FT-IR spectra of the LDHs samples are shown in Figure 2. As shown in Figure 2, a band near $3,420 \mathrm{~cm}^{-1}$ corresponds to the vibration bands of hydroxyls $(\mathrm{vOH})$. The peak moves to a higher 
wavenumber with increasing $\mathrm{Zn} / \mathrm{Al}$ ratio. The possible reason is that the ionic radius of $\mathrm{Al}^{3+}$ is smaller than that of $\mathrm{Zn}^{2+}$ and the charge number of $\mathrm{Al}^{3+}$ is greater than that of $\mathrm{Zn}^{2+}$, the electrostatic force between $\mathrm{Al}^{3+}$ and $\mathrm{OH}^{-}$is stronger than that of $\mathrm{Zn}^{2+}$ and $\mathrm{OH}^{-}$with increasing the $\mathrm{Zn} / \mathrm{Al}$ ratio. The bending mode of water molecules appears at $1,620 \mathrm{~cm}^{-1}$ and the intensity increases slightly with increasing $\mathrm{Zn} / \mathrm{Al}$ ratio. The sharp intense band at $1,364 \mathrm{~cm}^{-1}$ is the antisymmetric stretching of interlayer carbonate with high values of $\mathrm{Zn} / \mathrm{Al}$ ratio. Compared with the peak of $\mathrm{CO}_{3}{ }^{2-}$ in $\mathrm{CaCO} 3$ $\left(1,430 \mathrm{~cm}^{-1}\right)$, a large shift toward a lower wavenumber indicates that the $\mathrm{CO}_{3}{ }^{2-}$ intercalating into the interlayer is not free, and is interlayered with water molecules between with hydrogen bonds are formed [16]. The interlayer charge density and the coulomb repulsion between interlayer anions increases with decreasing $\mathrm{Zn} / \mathrm{Al}$ ratio, which results in a stronger peak of interlayer $\mathrm{CO}_{3}{ }^{2-}$ and a lower wave number $\left(1,357 \mathrm{~cm}^{-1}\right)$. The band at $794 \mathrm{~cm}^{-1}$ is the flexural vibration of $\mathrm{CO}_{3}{ }^{2-}$. The bands at $430 \mathrm{~cm}^{-1}$ and $560 \mathrm{~cm}^{-1}$ can be attributed to the lattice vibration modes, M-O and O-M-O vibration, respectively. The structural parameters of FT-IR are listed in Table 1.

Table 1. Fourier transform infrared spectroscopy (FT-IR) structure parameters of samples synthesized with different $\mathrm{Zn} / \mathrm{Al}$ molar ratios.

\begin{tabular}{|c|c|c|c|c|c|}
\hline \multirow{2}{*}{$\begin{array}{c}\text { molar } \\
\text { ratio }\end{array}$} & \multicolumn{5}{|c|}{ Wavenumber/cm ${ }^{-1}$} \\
\hline & $\begin{array}{c}\text { vibration bands } \\
\text { of }-\mathrm{OH}\end{array}$ & $\begin{array}{c}\text { Antisymmetric } \\
\text { stretching of } \mathrm{CO}_{3}{ }^{2-}\end{array}$ & $\begin{array}{c}\text { flexural vibration } \\
\text { of } \mathrm{CO}_{3}{ }^{2-}\end{array}$ & $\begin{array}{l}\text { lattice vil } \\
\qquad\left(\mathbf{Z n}^{2+}\right.\end{array}$ & $\begin{array}{l}\text { ration of } \\
\left.\mathrm{Al}^{3+}\right)\end{array}$ \\
\hline $1: 1$ & 3421 & 1357 & 793 & 560 & 430 \\
\hline $2: 1$ & 3446 & 1357 & 785 & 555 & 429 \\
\hline $3: 1$ & 3462 & 1364 & 768 & 553 & 430 \\
\hline
\end{tabular}

Figure 2. Fourier transform infrared spectroscopy (FT-IR) spectra of Zn-Al-LDHs with $\mathrm{Zn} / \mathrm{Al}$ molar ratios of (a) 1:1; (b) 2:1; and (c) 3:1.

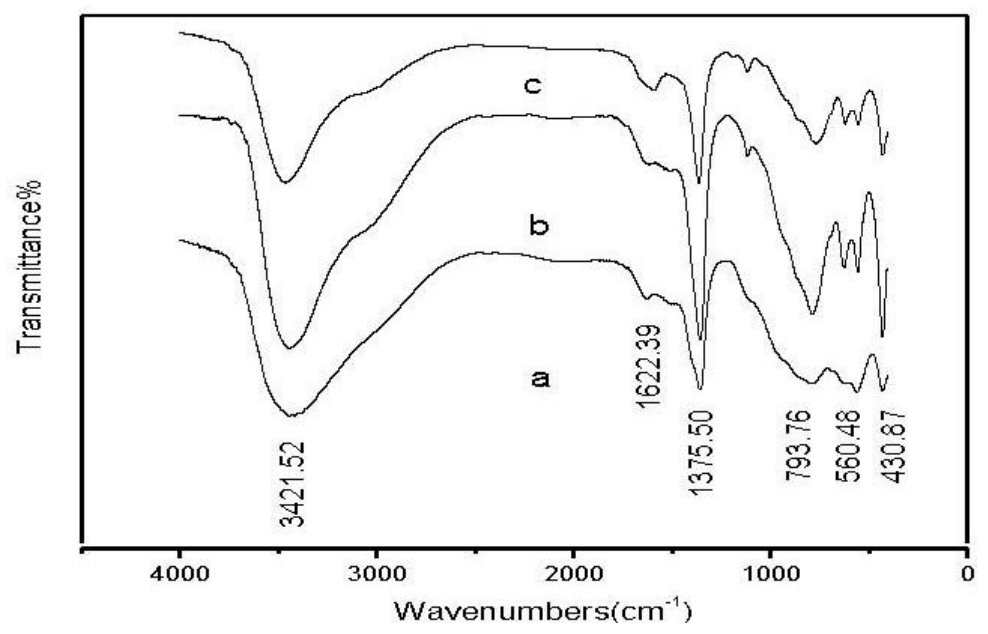

\subsubsection{Scanning Electron Microscope (SEM) Micrograph of Zn-Al-LDHs}

Figure 3 shows typical SEM micrographs of Zn-Al-LDHs with a Zn-Al molar ratio of 3:1. It can be seen that the existing lamellar particles have a rounded hexagonal shape, which is the typical structure of the hydrotalcite-like materials. 
Figure 3. Two examples of scanning electron microscope (SEM) images of Zn-Al-LDHs with a $\mathrm{Zn}-\mathrm{Al}$ molar ratio of 3:1.
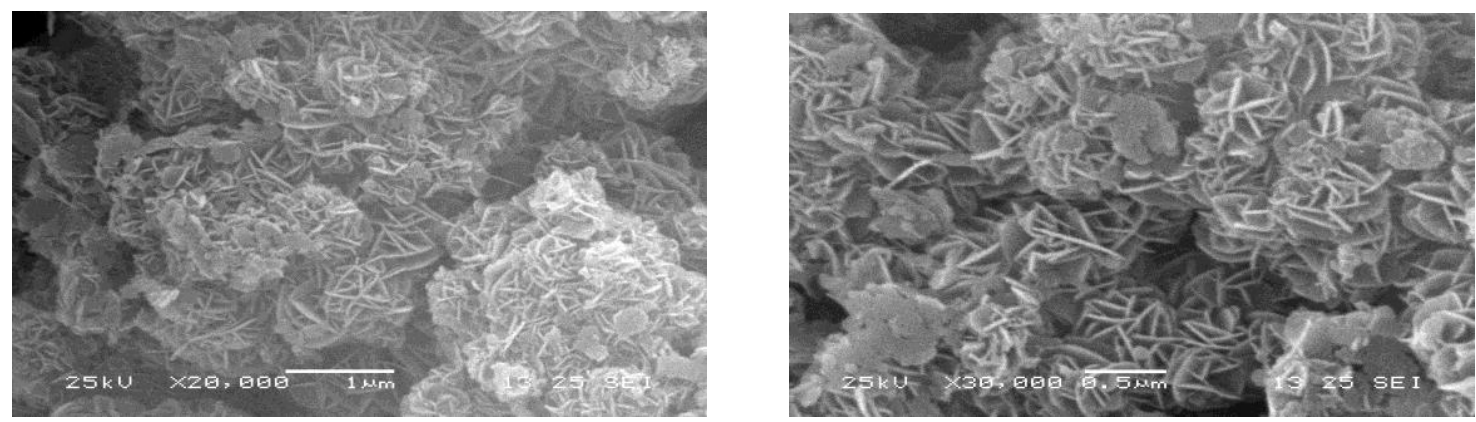

2.1.4. Particle Granularity and Specific Area Analysis of Zn-Al-LDHs

Figure 4 shows the particle granularity analysis pattern of $\mathrm{Zn}-\mathrm{Al}-\mathrm{LDH}$ s with a $\mathrm{Zn}$-Al molar ratio of $3: 1$. The range of the particle granularity was relatively narrow and the particle size showed normal distribution, which indicates the particle size distribution of powders was homogeneous and narrow.

The specific area of $\mathrm{Zn}-\mathrm{Al}-\mathrm{LDHs}$ with $\mathrm{Zn}-\mathrm{Al}$ ratio of 3:1 was analyzed by adsorption apparatus. The specific area of the particles is $43.48 \mathrm{~m}^{2} / \mathrm{g}$ and the pore volume is $0.2613 \mathrm{~cm}^{3} / \mathrm{g}$.

Figure 4. Particle granularity analysis pattern of $\mathrm{Zn}$-Al-hydrotalcite.

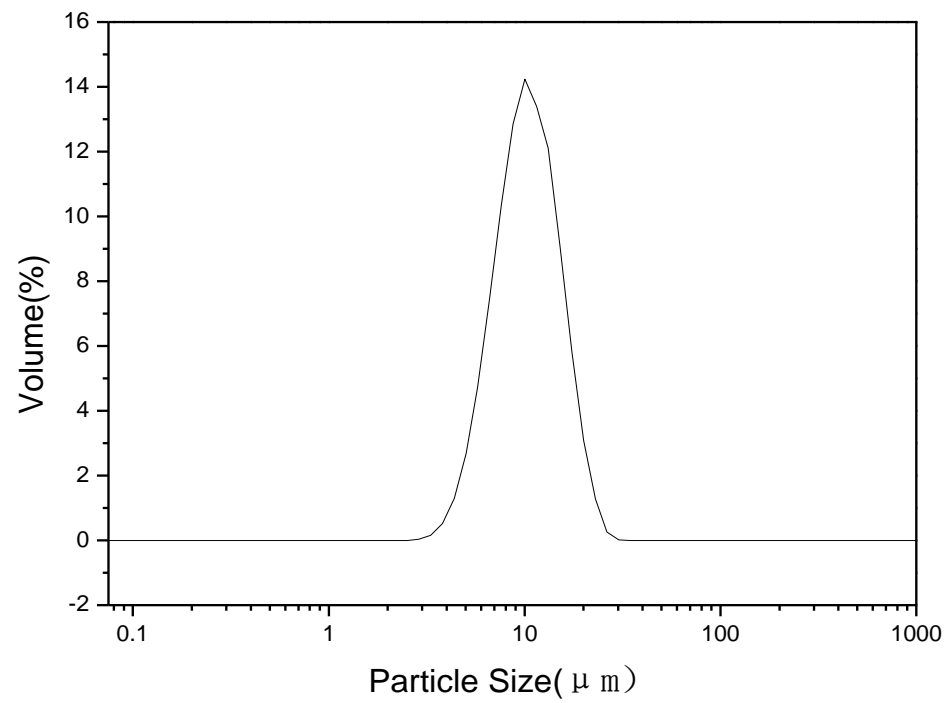

\subsection{Synergetic Thermal Stabilizing Effect of Zn-Al-LDHs with Metal Soap and $\beta$-Diketone}

$5 \mathrm{~g}$ PVC, $2.5 \mathrm{~g}$ DOP, and various amounts of Zn-Al-LDHs, Cast 2 and $\beta$-diketone were mixed. The results of static thermal aging tests carried out at $180 \pm 1{ }^{\circ} \mathrm{C}$ are shown in Table 2,3 and 4 . The thermal stability of PVC is defined by the time taken until black composition appeared. The $\beta$-diketone acts as a short-term stabilizer and the Zn-Al-LDHs acted not only as a long-term stabilizer because of hydroxyl, but also a short-term one due to $\mathrm{Zn}^{2+}$. However, with high content of $\mathrm{Zn}$, the performance of long-term stabilizer was weakened, and then $\mathrm{CaSt}_{2}$, a long-term stabilizer, was used to cooperate with Zn-Al-LDHs and $\beta$-diketone, which can enhance the stability of PVC greatly. 
2.2.1. The Effect of Zn-Al-LDHs, $\mathrm{CaSt}_{2}$ and $\beta$-Diketone on the Thermal Stability of PVC

As shown in Table 2, PVC mixture without Zn-Al-LDHs (serial number 1) became completely black within just $10 \mathrm{~min}$ at $180 \pm 1{ }^{\circ} \mathrm{C}$. When $0.04 \mathrm{~g} \mathrm{LDHs}$ (serial number 2) was added to the PVC, the stability time increases to $70 \mathrm{~min}$, indicating that the thermal stability is significantly enhanced. The reaction between $\mathrm{Zn}-\mathrm{Al}-\mathrm{CO}_{3}-\mathrm{LDHs}$ and $\mathrm{HCl}$ occurs in a two-step process. First of all, the counter ions $\mathrm{OH}^{-1}$ and $\mathrm{CO}_{3}{ }^{2-}$ between the $\mathrm{LDH}$ layers react with the $\mathrm{HCl}$ gas. Then, the $\mathrm{LDH}$ itself reacts with $\mathrm{HCl}$ with complete destruction of the LDH structure and formation of metal chlorides. The $\mathrm{Zn}-\mathrm{Al}-\mathrm{CO}_{3}-\mathrm{LDH}$ can react with labile chlorine atoms (such as allyl chloride), so it is easy to restrain the initial coloring and prevent the growth of "Polyolefin Structure" when it is used alone. As the amount of LDHs increased from 0 to $0.1 \mathrm{~g}$, there is a prominent increase in thermal stability of PVC. However, further addition of LDHs in PVC cannot enhance the thermal stability more, and weakens the stability instead. This phenomenon can be illustrated as the quantities of $\mathrm{Zn}$ increasing with the increment of LDHs, leading to the formation of $\mathrm{ZnCl}_{2}$ which can catalyze the dehydrochlorination. In $\mathrm{Zn}$-Al-LDHs, hydroxyl can absorb $\mathrm{HCl}$; furthermore, the existance of $\mathrm{Zn}$ can increase the initial stability, which makes good-initial coloring. However, the long-term stability is impaired due to the "zinc burning" as adding excess Zn-Al-LDHs. Compared with Mg-Al-LDHs, the PVC samples with $\mathrm{Zn}$-Al-LDHs are light yellow after $110 \mathrm{~min}$ in the aging test in this work, while the samples with Mg-Al-LDHs turned yellow inclining to black during the initial $20 \mathrm{~min}$ [17]. The optimum amount of LDHs is determined to be $0.1 \mathrm{~g}$ from Table 2. Xu et al. [18] investigated the thermal stability of $\mathrm{Zn}-\mathrm{Al}-\mathrm{CO}_{3}-\mathrm{LDH}$-incorporated $\mathrm{PVC}$ at high temperatures and found that LDHs facilitated dehydrochlorination at a lower temperature but LDHs can reduce the subsequent dehydrocarbonation and help to form more char-like carbonaceous materials. Unlike that investigation, the $\mathrm{CaSt}_{2}$ and $\beta$-diketone added here cooperated with LDHs to effectively reduce the formation of $\mathrm{ZnCl}_{2}$, then the dehydrochlorination of $\mathrm{HCl}$ was impaired even at initialization. The photos for the color changes of PVC with $0.1 \mathrm{~g}$ LDHs are displayed in Figure 5.

Table 2. The color changes for polyvinyl chloride (PVC) with different contents of LDHs, $0.2 \mathrm{~g} \mathrm{CaSt}_{2}$ and $0.25 \mathrm{~g} \beta$-diketone.

\begin{tabular}{ccccccccc}
\hline Serial & LDHss/ & \multicolumn{7}{c}{ Time/min and color stability } \\
\cline { 3 - 9 } number & $\mathbf{g}$ & $\mathbf{1 0}$ & $\mathbf{3 0}$ & $\mathbf{5 0}$ & $\mathbf{7 0}$ & $\mathbf{9 0}$ & $\mathbf{1 0 0}$ & $\mathbf{1 1 0}$ \\
\hline 1 & 0 & 7 & 7 & 7 & 7 & 7 & 7 & 7 \\
2 & 0.04 & 0 & 1 & 3 & 4 & 5 & 7 & 7 \\
3 & 0.06 & 0 & 1 & 3 & 4 & 5 & 5 & 7 \\
4 & 0.08 & 0 & 0 & 0 & 3 & 4 & 5 & 6 \\
5 & 0.1 & 0 & 0 & 0 & 1 & 1 & 3 & 3 \\
6 & 0.2 & 0 & 0 & 1 & 4 & 5 & 5 & 6 \\
7 & 0.3 & 0 & 3 & 3 & 4 & 5 & 6 & 6 \\
\hline
\end{tabular}

Color code: 0-white; 1-milky; 2-pink; 3-light yellow; 4-yellow; 5-black and yellow; 6-brown; 7-black. 
Figure 5. The color stability of PVC with $0.1 \mathrm{~g} \mathrm{LDHs}, 0.2 \mathrm{~g} \mathrm{CaSt}_{2}$ and $0.25 \mathrm{~g} \beta$-diketone.

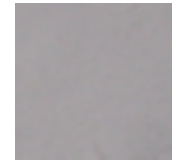

$10 \min$

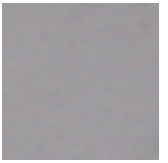

$20 \mathrm{~min}$

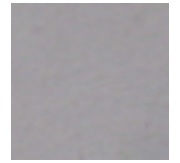

$30 \min$

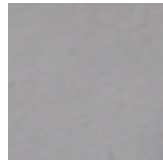

$40 \min$

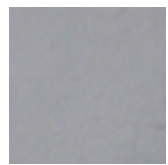

$50 \mathrm{~min}$

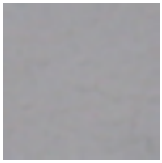

$60 \min$

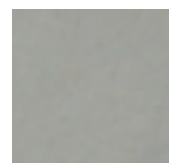

$70 \min$

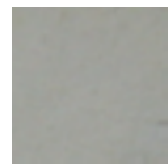

$80 \mathrm{~min}$

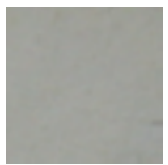

$90 \min$

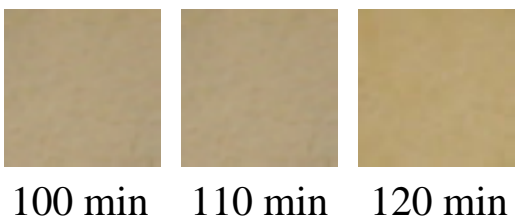

2.2.2. The Effect of Varying the Amount of $\mathrm{CaSt}_{2}$ on the PVC

Table 3 shows the color changes of PVC with various amounts of $\mathrm{CaSt}_{2}$ added. It is clear that the short-term stabilization of PVC is enhanced with increasing quantities of $\mathrm{CaSt}_{2}$. The $\mathrm{CaSt}_{2}$ not only absorbs $\mathrm{HCl}$, but also exchanges ions with $\mathrm{ZnCl}_{2}$ in the PVC-Zn-Al-LDHs systems, which could be expressed as following:

$$
\mathrm{ZnCl}_{2}+\mathrm{Ca}(\mathrm{OOCR})_{2} \longrightarrow \mathrm{Zn}(\mathrm{OOCR})_{2}+\mathrm{CaCl}_{2}
$$

The active $\mathrm{ZnSt}_{2}$ is generated and the undesirable $\mathrm{ZnCl}_{2}$ is consumed. The product $\mathrm{ZnSt}_{2}$ can scavenge $\mathrm{HCl}$ and react with the labile chlorine (allylic chlorine) atoms on the PVC chain. From Table 3, the optimum amount of $\mathrm{CaSt}_{2}$ is thought to be $0.15 \mathrm{~g}$. The photos for the color changes of PVC with $0.15 \mathrm{~g} \mathrm{CaSt}_{2}$ are presented in Figure 6.

Table 3. The color changes for PVC with different contents of $\mathrm{CaSt}_{2}, 0.1 \mathrm{~g} \mathrm{LDHs}$, and $0.25 \mathrm{~g} \beta$-Diketone.

\begin{tabular}{lllllllll}
\hline Serial number & $\mathbf{C a S t}_{2} / \mathbf{g}$ & \multicolumn{9}{c}{ Time/min and color stability } \\
\cline { 2 - 9 } & & $\mathbf{1 0}$ & $\mathbf{3 0}$ & $\mathbf{5 0}$ & $\mathbf{7 0}$ & $\mathbf{9 0}$ & $\mathbf{1 0 0}$ & $\mathbf{1 1 0}$ \\
\hline 1 & 0.45 & 0 & 1 & 1 & 3 & 4 & 4 & 4 \\
2 & 0.35 & 0 & 1 & 1 & 3 & 3 & 3 & 7 \\
3 & 0.25 & 0 & 1 & 1 & 3 & 4 & 4 & 6 \\
4 & 0.2 & 0 & 0 & 0 & 1 & 1 & 3 & 3 \\
5 & 0.15 & 0 & 0 & 0 & 0 & 1 & 3 & 3 \\
6 & 0.1 & 0 & 0 & 1 & 3 & 3 & 4 & 5 \\
7 & 0.05 & 0 & 0 & 1 & 3 & 6 & 7 & 7 \\
\hline
\end{tabular}

Color code: 0-white; 1-milky; 2-pink; 3-light yellow; 4-yellow; 5-black and yellow; 6-brown; 7-black.

Figure 6. The color stability of PVC with $0.1 \mathrm{~g} \mathrm{LDHs,} 0.15 \mathrm{~g} \mathrm{CaSt}_{2}$ and $0.25 \mathrm{~g} \beta$-diketone.

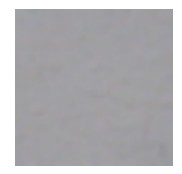

$10 \min$

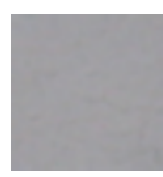

$20 \min$

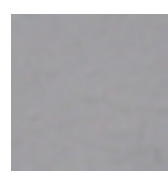

$30 \min$

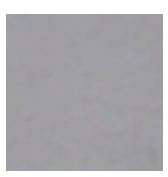

$40 \mathrm{~min}$

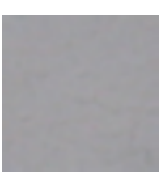

$50 \min$

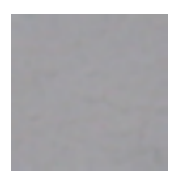

$60 \min$

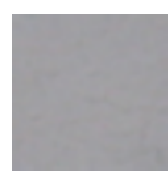

70 min

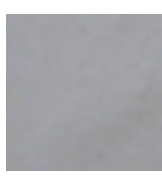

80 min 
Figure 6. Cont.

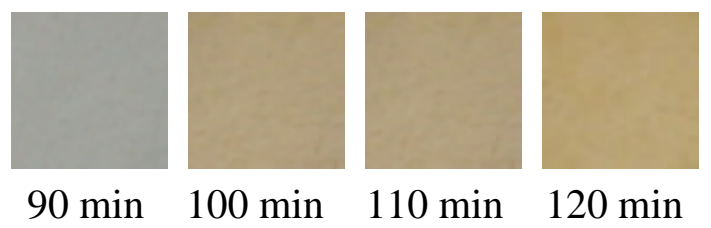

2.2.3. The Effect of Varying the Amount of $\beta$-Diketone on the PVC

The color stability of PVC with $\beta$-Diketone is shown in Table 4. For PVC mixtures without any $\beta$-Diketone or with a low amount of $\beta$-Diketone (series 4 and 5), the discoloration time is only 10 min. The later color change from yellow to black is sudden. When the quantity of $\beta$-diketone is $0.25 \mathrm{~g}$, the initial color is stable to some degree, as well as the later color, which means that the optimum amount of $\beta$-Diketone is $0.25 \mathrm{~g}$. The $\beta$-diketone behaves as a short-term co-stabilizer and increases initial color stability. The acetylacetonates substitute allylic chlorides inhibiting the formation of long polyenes and resulting in no discoloration of the polymer [19]. The reaction of $\beta$-Diketone with polyvinyl chloride is presented in Figure 7.

Figure 7. The reaction of $\beta$-Diketone with polyvinyl chloride.

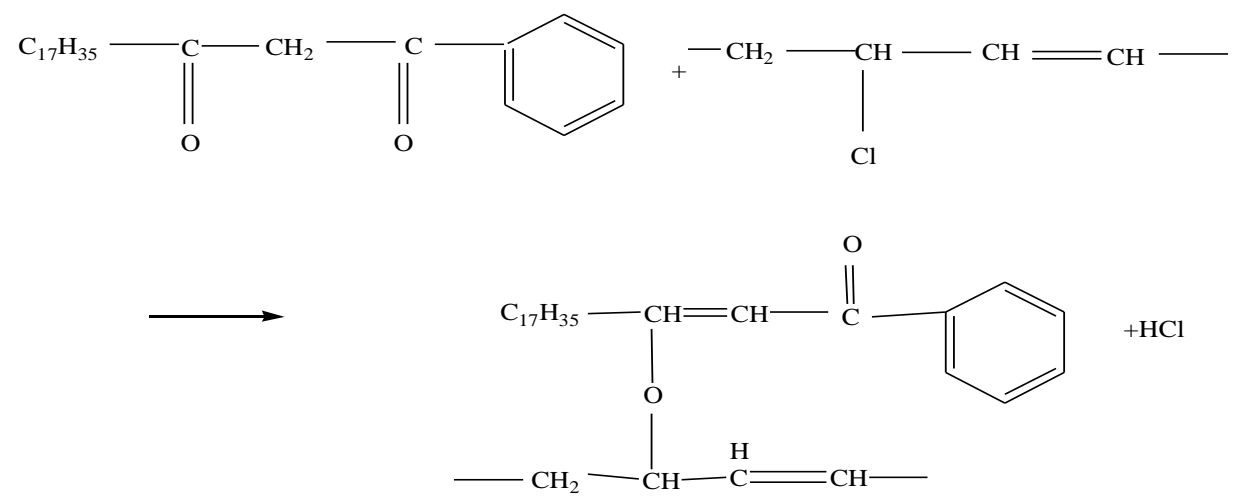

The photos for the color changes of PVC without $\beta$-diketone are shown in Figure 8.

Table 4. The color changes observed for PVC with different contents of $\beta$-diketone, $0.1 \mathrm{~g}$ LDHs and $0.15 \mathrm{~g} \mathrm{CaSt}_{2}$.

\begin{tabular}{cllllllll}
\hline \multirow{2}{*}{$\begin{array}{l}\text { Serial } \\
\text { number }\end{array}$} & $\boldsymbol{\beta}$-Diketone/g & \multicolumn{8}{c}{ Time/min and color stability } \\
\cline { 2 - 9 } & & $\mathbf{1 0}$ & $\mathbf{3 0}$ & $\mathbf{5 0}$ & $\mathbf{7 0}$ & $\mathbf{9 0}$ & $\mathbf{1 0 0}$ & $\mathbf{1 1 0}$ \\
\hline 1 & 0.35 & 0 & 1 & 3 & 3 & 5 & 7 & 7 \\
2 & 0.25 & 0 & 0 & 0 & 0 & 1 & 3 & 3 \\
3 & 0.15 & 0 & 0 & 1 & 3 & 4 & 5 & 6 \\
4 & 0.05 & 1 & 1 & 2 & 2 & 3 & 4 & 7 \\
5 & 0 & 2 & 2 & 2 & 2 & 4 & 6 & 7 \\
\hline
\end{tabular}

Color code: 0-white; 1-milky; 2-pink; 3-light yellow; 4-yellow; 5-black and yellow; 6-brown; 7-black. 
Figure 8. The color stability of PVC with $0.1 \mathrm{~g} \mathrm{LDHs,} 0.15 \mathrm{~g} \mathrm{CaSt}_{2}$ and $0 \mathrm{~g} \beta$-diketone.

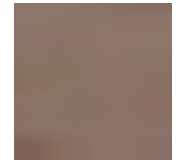

$10 \min$

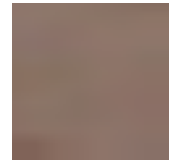

$20 \min$

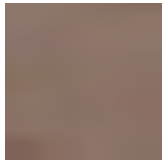

$30 \min$

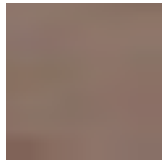

$40 \mathrm{~min}$

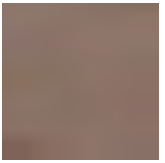

$50 \mathrm{~min}$

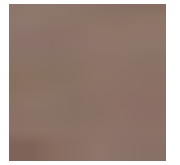

$60 \mathrm{~min}$

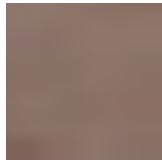

$70 \mathrm{~min}$

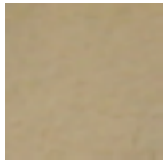

$80 \min$

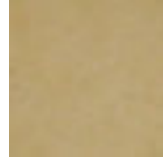

$90 \mathrm{~min} \quad 100 \mathrm{~min} \quad 110 \mathrm{~min}$

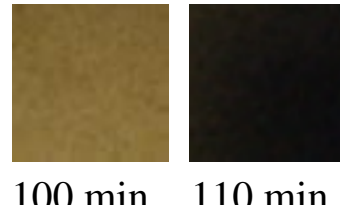

\section{Experimental Section}

\subsection{Materials}

$\mathrm{ZnO}, \mathrm{NaAlO}_{2}, \mathrm{Na}_{2} \mathrm{CO}_{3}, \mathrm{NaOH}, \beta$-diketones, $\mathrm{CaSt}_{2}$ and DOP were of analytical grade. The PVC resin (SG-3) used in the experiment was provided by Beijing Huaer.

\subsection{Synthesis of $\mathrm{Zn}-\mathrm{Al}-\mathrm{CO}_{3}-\mathrm{LDHs}$}

A $\mathrm{NaAlO}_{2}$ solution was added slowly to the mixed solution containing $\mathrm{ZnO}$ and $\mathrm{Na}_{2} \mathrm{CO}_{3}$ at $90{ }^{\circ} \mathrm{C}$. The resulting solution was continuously stirred for 2 hours and the pHwas adjusted from 9 to 10 using $\mathrm{NaOH}$ solution. Subsequently, the solution was maintained at $100{ }^{\circ} \mathrm{C}$ for 16 hours in an autoclave. Subsequently, the slurry was aged at $80{ }^{\circ} \mathrm{C}$ for 8 hours. Finally, the precipitate was filtered, washed and dried.

\subsection{Characterization Techniques for Hydrotalcites}

Powder XRD patterns were recorded using a Rigaku D/max-2500 diffractometer $(\mathrm{Cu} K \alpha$ radiation, scan speed of $8 \% \mathrm{~min}$ ). Infra red spectra were performed on a Nicolet Nexus-670 FT-IR spectrometer in the range $4000-400 \mathrm{~cm}^{-1}$ using $\mathrm{KBr}$ pellets. The surface morphology of synthesized hydrotalcite was observed using a JSM-6360 scanning electron microscope. The specific area of Zn-Al-LDHs was determined on TriStar3000 BET surface area measurement. The particle granularity was recorded by a laser particle analyzer.

\subsection{Static Thermal Aging Test}

Mixtures containing $5 \mathrm{~g}$ PVC powder, $2.5 \mathrm{~g}$ dioctylphthalate (DOP), various amounts of LDHs, $\mathrm{CaSt}_{2}$ and $\beta$-diketone were blended in a double-roller mixer for $5 \mathrm{mins}$ at $180{ }^{\circ} \mathrm{C}$. The resulting composites were molded to sheets with a thickness of $1.0 \mathrm{~mm}$ and cut into $3 \mathrm{~cm} \times 2 \mathrm{~cm}$ strips. These strips were placed in a Thermal Aging Test Box at $180 \pm 1{ }^{\circ} \mathrm{C}$ and subjected to static thermal aging. The strips were taken out of the box every 10 or 20 mins and examined visually. 


\section{Conclusions}

In this research, the $\mathrm{Zn}-\mathrm{Al}-\mathrm{CO}_{3}-\mathrm{LDHs}$ were prepared by a clean-route synthesis method. The hydrotalcite has a layered structure. The LDHs can be successfully synthesized at three different ratios of 3:1, 2:1 and 1:1 and the Zn-Al-LDHs have high crystalline and integrated crystalline structures with $\mathrm{Zn} / \mathrm{Al}$ molar ratio of $2: 1$. The $\mathrm{Zn}-\mathrm{Al}-\mathrm{CO}_{3}-\mathrm{LDHs}$ can react with labile chlorine atoms, so it is easy to restrain the initial coloring and prevent the growth of "Polyolefin Structure" when it is used alone. The $\mathrm{Zn}-\mathrm{Al}-\mathrm{CO}_{3}-\mathrm{LDH}$ bear a synergistic effect with $\mathrm{CaSt}_{2}$ and $\beta$-diketone on the stability of PVC with the optimum quantity of $0.1 \mathrm{~g}$ LDHs, $0.15 \mathrm{~g} \mathrm{CaSt}_{2}$ and $0.25 \mathrm{~g} \beta$-diketone in $5 \mathrm{~g}$ PVC.

\section{Acknowledgements}

This work was supported by Natural Science Foundation of China (91023031).

\section{References}

1. Chen, G.M. Preparation of a poly (vinyl chloride)/layered double hydroxide nanocomposite with a reduced heavy-metal thermal stabilizer. J. Appl. Polym. Sci. 2007, 106, 817-820.

2. Mohamed, N.A.; Yassin, A.A.; Khalil, K.D.; Sabaa, M.W. Organic thermal stabilizers for rigid poly(vinyl chloride) I. Barbituric and thiobarbituric acids. Polym. Degrad. Stab. 2000, 70, 5-10.

3. Murphy, J. Heat stabilizers. Plastic. Add. Compound. 1999, 1, 24-29.

4. Yang, Z.H.; Shu, W.Y.; Long, H.Z.; Li, X.H. Influence of rare earth heating stabilizer on heating stabilizing property of PVC. Chin. Rare Earths 1999, 20, 60-62.

5. Martin, K.J.; Pinnavaia, T.J. Layered double hydroxides as supported anionic reagents halied ion reactivity in $\left[\mathrm{Zn}_{2} \mathrm{Cr}(\mathrm{OH})_{6}\right] \mathrm{X} \cdot \mathrm{nH}_{2} \mathrm{O}$. J. Am. Chem. Soc. 1986, 108, 541-542.

6. Allmann, R. The crystal structure of pyroaurite. Acta. Crystallogr. B. 1968, 24, 972-977.

7. Taylor, H.F.W. Crystal structures of some double hydroxide minerals. Mineral. Mag. 1973, 39, 377-389.

8. He, J.; Wei, M.; Li, B.; Kang, Y.; Evans, D.G.; Duan, X. Preparation of layered double hydroxides. Struct. Bond. 2006, 119, 89-119.

9. Li, F.; Duan, X. Applications of layered double hydroxides. Struct. Bond. 2006, 119, 193-223.

10. Vaccari, A. Preparation and catalytic properties of cationic and anionic clays. Catal. Today 1998, $41,53-71$.

11. Vaccari, A. Clays and catalysis: A promising future. Appl. Clay Sci. 1999, 14, 161-198.

12. Van der Ven, L.; Van Gemert, M.L.M.; Batenburg, L.F.; Keern, J.J.; Gielgens, L.H.; Koster, T.P.M.; Fischer, H.R. On the action of hydrotalcite-like clay materials as stabilizers in polyvinylchloride. Appl. Clay Sci. 2000, 17, 25-34.

13. Wang, X.; Zhang, Q. Effect of hydrotalcite on the thermal stability, mechanical properties, rheology and flame retardance of poly (vinyl chloride). Polym. Int. 2004, 53, 698-707.

14. Lin, Y.J.; Li, D.Q.; Evans, D.G.; Duan, X. Modulating effect of $\mathrm{Mg}-\mathrm{Al}-\mathrm{CO}_{3}$ layered double hydroxides on the thermal stability of PVC resin. Polym. Degrad. Stab. 2005, 88, 286-293.

15. Levchik, S.V.; Weil, E.D. Overview of the recent literature on flame retardancy and smoke suppression in PVC. Polym. Adv. Echnol. 2005, 16, 707-716. 
16. Hernandez-Moreno, M.J.; Ulibarri, M.A.; Rendon, J.L.; Serna, C.J. IR characteristics of hydrotalcite-like compounds. Phys. Chem. Miner. 1985, 12, 34-38.

17. Yi, S.; Yang, Z.H.; Wang, S.W.; Liu, D.R.; Wang, S.Q.; Liu, Q.Y.; Chi, W.W. Effects of $\mathrm{MgAlCe}-\mathrm{CO}_{3}$ layered double hydroxides on the thermal stability of PVC resin. J. Appl. Polym. Sci. 2011, 119, 2620-2626.

18. Xu, Z.P.; Saha, S.K.; Braterman P.S.; D’Souza, N. The effect of Zn, Al layered double hydroxide on thermal decomposition of poly (vinyl chloride). Polym. Degrad. Stab. 2006, 91, 3237-3244.

19. Gupta, S.; Agarwal, D.D.; Banerjee, S. Synergistic combination of metal stearates and $\beta$-diketones with hydrotalcites in poly(vinyl chloride) stabilization. J. Appl. Polym. Sci. 2009, 112, 1056-1062.

(C) 2011 by the authors; licensee MDPI, Basel, Switzerland. This article is an open access article distributed under the terms and conditions of the Creative Commons Attribution license (http://creativecommons.org/licenses/by/3.0/). 